\title{
Skin Between the Eyebrows
}

National Cancer Institute

\section{Source}

National Cancer Institute. Skin Between the Eyebrows. NCI Thesaurus. Code C142317.

The integumentary covering located medial to the orbital ridges and superior to the nose. 